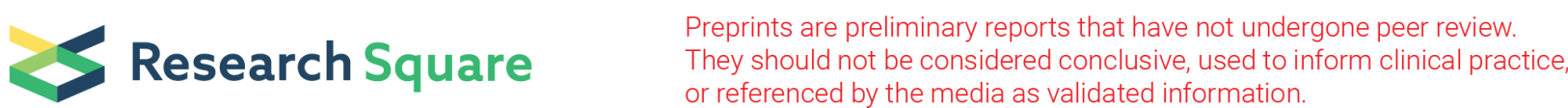

\section{Shaping the future of temperate forests in Europe: why outdoor recreation matters}

Marek Giergiczny ( $\nabla$ mgiergiczny@wne.uw.edu.pl )

University of Warsaw

Jette Jacobsen

University of Copenhagen

Klaus Glenk

Department of Rural Economy SRUC

Jürgen Meyerhoff

Technische Universität Berlin

Jens Abildtrup

Université de Lorraine

Fitalew Agimass

Griffith University

Mikołaj Czajkowski

University of Warsaw

Michela Faccioli

University of Exeter Business School

Tomasz Gajderowicz

University of Warsaw

Michael Getzner

Vienna University of Technology

Thomas Lundhede

University of Copenhagen

Marius Mayer

Universität Innsbruck

Alistair McVittie

SRUC https://orcid.org/0000-0002-7128-7446

Roland Olschewski

WSL Swiss Federal Research Institute

Milan Ščasný

Charles University

Niels Strange

University of Copenhagen

Sviataslau Valasiuk

University of Warsaw

Article

Keywords: forests, economic value, forest recreation, European forests

Posted Date: August 26th, 2021

DOI: https://doi.org/10.21203/rs.3.rs-841881/v1

License: (9) (7) This work is licensed under a Creative Commons Attribution 4.0 International License. Read Full License 


\section{Abstract}

Forests play a fundamental role in the economy, in climate change mitigation and in halting the loss of biodiversity. The economic value of goods and services provided to the societies by forests, including forest-based recreation, is highly dependent on the way in which forests are managed. On a European scale, forests are diverse and managed in many ways. Yet there has been no large-scale assessment to date of the economic value of forests recreation across Europe. In this paper we systematically apply stated and revealed preference-based valuation methods to investigate public preferences for forest visits in ten European countries (Austria, Belarus, Czech Republic, Denmark, France, Germany, Poland, Slovakia, Scotland, Switzerland). We observe substantial recreational value measured by the consumer surplus ranging from $€ 55$ to $€ 648$ per person per year (PPP adjusted, 2017). Compared to the gross value added of forestry and timber production, gross recreational benefits are, except for Belarus, on par or larger. Additionally, we find that forests of particular characteristics - more complex forest structures and forests with taller and older trees - are preferred and generate higher recreational values. These results provide a robust basis for evaluating the societal consequences of future forest management policies in Europe and the design of its forest landscapes.

\section{Main Text}

Like many of the world's forests, the forests of Europe have seen dramatic changes in composition and distribution throughout their history. Today's forests are undergoing another important period of transition. Climate change will increasingly impact disturbance regimes through, for example, prolonged periods of heat and drought, increased wildfire frequency and increased forest vulnerability to pests and diseases. In turn, changed disturbance regimes will inevitably shape the composition and structure of many forests, whether in a managed or unmanaged way ${ }^{1}$. At the same time, forest expansion via tree planting has been considered an important strategy to address environmental challenges such as climate change, drinking water shortages and halting the loss of biodiversity while satisfying public demand for outdoor recreation ${ }^{2}$. Policy makers and forest managers will have to respond to these drivers of forest transition. Decisions made over coming years will influence what forests (both currently existing and new) will look like in the second half of the century, where they will be located. Forest allocation and management decisions should strive to optimize the benefits that future forests will provide to society. Therefore, decisions on forest management and forest expansion should be based on robust evidence concerning the relative importance and value of a wide range of the ecosystem services provided by forests ${ }^{3}$.

\section{Estimating the value of forest recreation}

Forest recreation can be considered as an essential forest ecosystem service. However, its value is often ignored when future forest management strategies are assessed ${ }^{4,5}$. This study seeks to inform forest-related policy development over large areas of Europe by (i) quantifying the societal value of forest recreation, (ii) demonstrating its relative importance compared to provisioning services (value of forestry and logging), and (iii) investigating the dependency of recreational values on forest structural attributes. For over half a century, economists have estimated the monetary value of the recreational experience of forest visits ${ }^{6}$. An early review of studies conducted between 1979 and 2001 found that benefits to the economy per forest trip varied between 0.6 and 112 euros (median 4.5 euros) for forest sites across Europe ${ }^{7}$. Site-specific characteristics of forests such as the age and diversity of trees explained variation in recreational benefits. Few studies at the country level have since highlighted the contribution of forest structural attributes to recreational value ${ }^{8,9}$. Given EU wide strategic policies and initiatives such as the Forest Strategy ${ }^{10}$ and the Biodiversity Strategy for $2030^{11}$, site-specific and country-specific assessments are no longer sufficient. Subsequently, we provide a first assessment of the order of magnitude of forest recreational values by systematically quantifying the economic value of forest recreation and its dependency on forest structural attributes across a large number (ten) of European countries and associated ecological, economic and social contexts.

Through nationwide surveys of representative samples of the population, a total of 9,429 respondents in the ten study countries were asked to reveal information about their last forest visit and state their preferences for forest structures via a discrete choice experiment (DCE) ${ }^{12}$. We find that the economic benefits of forest recreation are large, and at least of the same order of magnitude compared to the value of forestry and logging. We also find that Europeans across countries and contexts share recreational preferences. Our findings are not only important for identifying key descriptors for what shapes the recreational values of forests, but also provide important information for framing future European forest policies and the discussion on how forests should be effectively managed to increase their contribution to societal goals.

\section{The value of recreation}

Information on travel distance, accounting for both travel costs in the narrow sense and the travel time element, was used to calculate the consumer surplus, reflecting the economic benefits of forest recreation. We find that in all countries considered in the study that the economic value of forest recreation is substantial and apart from Belarus larger than the value of forestry and logging activities (Table 1 and Figure 1).

The number of visits to the forest last visited by respondents varies considerably across the countries (between 11-60 visits per year). While "experiencing nature" was selected by respondents in most of the countries as the primary purpose of their last forest visit, the large array of stated purposes of the forest visit also includes walking, hiking, dog-walking, mushroom picking and time spent with children (Table S 1, Supplementary Materials). Therefore, the forest itself matters as a place for the enjoyment of nature, which is often combined with a wide range of outdoor activities. In addition to the variation in distance travelled and the number of visits per year, differences in benefit estimates across the countries are the result of variations in country specific unit travel and the opportunity costs of time.

Of all one-day forest visits between 24 per cent (Belarus) and 80 per cent (Denmark) took place on weekdays. The remainder were visits during weekends and public holidays (referred to in what follows as weekend visits). Respondents also travel farther on weekend visits than during the week (Table 2). Reflecting differences in distances travelled between weekdays and weekends, consumer surplus estimates per visit are higher for weekends than weekdays. Given the 
overall higher number of visits during weekdays, this does not necessarily translate into higher per capita economic benefits of forest recreation at weekends. Nevertheless, it demonstrates that forests both closer to home (more likely to be visited during the week) and farther away (more likely to be visited during weekends) play an important role in realizing the recreational benefits.

Table 1. Economic values (consumer surplus, CS) of forest recreation and comparison with gross value added of forestry and logging activities (all values in EUR).

\begin{tabular}{|c|c|c|c|c|c|c|c|c|c|c|}
\hline & AUT & BLR & $\mathrm{CHE}$ & CZE & DEU & DNK & FRA & POL & SVK & sco \\
\hline CS weekday per visit & 6.9 & 0.9 & 4.1 & 1.9 & 2.6 & 3.6 & 6.4 & 2.5 & 5.3 & 6.9 \\
\hline CS weekend per visit & 20.3 & 1.8 & 14.7 & 7.7 & 21.7 & 13.8 & 21.1 & 7.3 & 7.8 & 14.1 \\
\hline CS weekday per visitor per year & 202.8 & 2.5 & 183.3 & 42.1 & 64.8 & 142.3 & 103.0 & 47.3 & 88.7 & 112.1 \\
\hline CS weekend per visitor per year & 365.6 & 14.3 & 219.0 & 128.8 & 391.9 & 136.3 & 339.7 & 162.0 & 147.2 & 123.4 \\
\hline Total CS per visitor per year & 568.4 & 16.8 & 402.3 & 170.9 & 456.7 & 278.6 & 442.8 & 209.3 & 235.9 & 235.5 \\
\hline Total CS per visitor per year (2017, PPPa adjusted) & 648.0 & 55.1 & 332.2 & 320.2 & 537.2 & 263.2 & 489.6 & 451.5 & 435.1 & 267.6 \\
\hline $\begin{array}{l}\text { Aggregate consumer surplus per year (nominal EUR millions, } \\
\text { 2017) }\end{array}$ & 3,545 & 102 & 2,526 & 1,291 & 23,788 & 1,080 & 17,203 & 5,920 & 854 & 737 \\
\hline $\begin{array}{l}\text { Annual gross value added of forestry and logging activities } \\
\text { (nominal EUR millions, } 2017^{b} \text { ) }\end{array}$ & 1,048 & 215 & 345 & 1,120 & 3,374 & 226 & 3,351 & 1,921 & 407 & 370 \\
\hline $\begin{array}{l}\text { Ratio: Aggregate consumer surplus/ Gross value added of } \\
\text { forestry and logging activities }\end{array}$ & 3.38 & 0.47 & 7.32 & 1.15 & 7.05 & 4.78 & 5.13 & 3.08 & 2.10 & 1.99 \\
\hline
\end{tabular}

Note: AUT: Austria; BLR: Belarus; CHE: Switzerland; CZE: Czech Republic; DEU: Germany; DNK: Denmark; FRA: France; POL: Poland; SVK: Slovakia; SCO: Scotland

a Purchasing power parity

${ }^{\mathrm{b}}$ https://appsso.eurostat.ec.europa.eu/nui/submitViewTableAction.do, For SCO, mid 2017 values:

https://www.ons.gov.uk/peoplepopulationandcommunity/populationandmigration/populationestimates/bulletins/annualmidyearpopulationestimates/mid20 For BLR: FAO (2014). Contribution of the forestry sector to national economies, 1990-2011, by A. Lebedys and Y. Li. Forest Finance Working Paper FSFM/ACC/09. FAO, Rome. - p.82.

Table 2. Statistics on respondents' forest visits and census.

\begin{tabular}{|c|c|c|c|c|c|c|c|c|c|c|}
\hline & AUT & BLR & $\mathrm{CHE}$ & CZE & DEU & DNK & FRA & POL & SVK & sco \\
\hline Number of visits per year and visitor & 47.4 & 10.7 & 59.6 & 38.9 & 43.0 & 49.4 & 32.2 & 41.1 & 35.6 & 25.0 \\
\hline Proportion of weekend trips & 0.38 & 0.74 & 0.25 & 0.43 & 0.42 & 0.2 & 0.5 & 0.54 & 0.53 & 0.35 \\
\hline $\begin{array}{l}\text { Mean (std dev.) roundtrip distance on weekdays } \\
\text { in km }\end{array}$ & $\begin{array}{l}10.45 \\
(15.97)\end{array}$ & $\begin{array}{l}21.7 \\
(26.17)\end{array}$ & $\begin{array}{l}5.72 \\
(6.41)\end{array}$ & $\begin{array}{l}14.28 \\
(17.61)\end{array}$ & $\begin{array}{l}9.71 \\
(11.39)\end{array}$ & $\begin{array}{l}7.45 \\
(7.51)\end{array}$ & $\begin{array}{l}21.28 \\
(24.06)\end{array}$ & $\begin{array}{l}14.74 \\
(19.81)\end{array}$ & $\begin{array}{l}13.72 \\
(17.79)\end{array}$ & $\begin{array}{l}32.41 \\
(37.65)\end{array}$ \\
\hline $\begin{array}{l}\text { Mean (std dev.) roundtrip distance at weekends } \\
\text { in km }\end{array}$ & $\begin{array}{l}26.83 \\
(45.87)\end{array}$ & $\begin{array}{l}32.83 \\
(35.64)\end{array}$ & $\begin{array}{l}10.89 \\
(16.05)\end{array}$ & $\begin{array}{l}30.85 \\
(43.97)\end{array}$ & $\begin{array}{l}27.41 \\
(40.92)\end{array}$ & $\begin{array}{l}20.53 \\
(27.82)\end{array}$ & $\begin{array}{l}45.95 \\
(53.51)\end{array}$ & $\begin{array}{l}40.45 \\
(54.70)\end{array}$ & $\begin{array}{l}42.18 \\
(72.88)\end{array}$ & $\begin{array}{l}54.73 \\
(59.07)\end{array}$ \\
\hline $\begin{array}{l}\text { Proportion of survey respondents who have } \\
\text { visited forests during the last year }\end{array}$ & 0.86 & 0.79 & 0.90 & 0.87 & 0.75 & 0.84 & 0.74 & 0.90 & 0.81 & 0.71 \\
\hline $\begin{array}{l}\text { Derived population } 18+\text { who visits forests } \\
\text { (million visits per week) }\end{array}$ & 6.24 & 6.07 & 6.28 & 7.55 & 52.08 & 3.87 & 38.86 & 28.29 & 3.62 & 3.13 \\
\hline
\end{tabular}

\section{Recreational value and forest characteristics}

Our study also finds that people face trade-offs between distance travelled and forest characteristics when choosing which forest to visit. In a series of choice questions, we repeatedly asked respondents whether they would prefer to visit the forest they last visited or, alternatively, one of two depicted hypothetical forests that differed from each other and across choice questions in terms of forest structural attributes and travel distances (Figure 2). The characteristics considered were forest type, tree species, age structure, tree height, and amount of deadwood (as an indicator of biodiversity).

The results of the DCE emphasize that forest characteristics matter for the level of recreational benefits obtained from forest visits. The preference for a particular forest structural attribute was estimated as the respondents' willingness to travel (WTT) a certain distance to visit a forest with such a characteristic, 
relative to a baseline distance (Figure 3). Higher WTT reflects a greater importance of a forest characteristic for forest visitation decisions. We find that, relative to other characteristics, WTT estimates are highest for tree height (Figure 3, panel e). Smaller but still significant WTT values were observed for other forest characteristics. Mixed forests composed of two species (one coniferous species and one broadleaf species) tend to have a higher WTT compared to single species monocultures (Figure 3, panel a). Forests comprising a mix of one broadleaved and one coniferous species tend to be preferred to forests consisting of a mix of two broadleaved or coniferous species (Figure 3, panel b). Further, across all the countries, mixed forests consisting of four species are preferred to forests with fewer species (Figure 3, panel c). In all the countries (except Switzerland), forests with multiple layers are perceived to be more attractive than single layered forests (Figure 3, panel d). Respondents share a common preference for forests to have some (rather than no) deadwood, although related WTT is comparatively low (Figure 3, panel f). Interestingly, a medium amount of deadwood is preferred over a high amount or no deadwood for most of the study countries, pointing to an inverted U-shaped relationship between recreational benefits and the deadwood level, which is an important indicator of biodiversity. Across the countries, there are considerable differences regarding the relative strength of preferences. For example, a forest with trees that are $24 \mathrm{~m}$ in height relative to a baseline forest with trees that are $8 \mathrm{~m}$ in height increases visitor's willingness to travel (WTT) — from $5.9 \mathrm{~km}$ in Denmark to $34.1 \mathrm{~km}$ in Poland. Similarly, increased WTT for multi-aged vs. single-aged forest varies from $1 \mathrm{~km}$ in Switzerland to $19.3 \mathrm{~km}$ in Slovakia.

To understand patterns in preferences for forest characteristics, and identify any dominance, we aggregated the results across all 10 countries considered in the study and calculated the number of times WTT for each forest attribute level is significantly greater than the WTT for the remaining levels of that attribute (Figure 4). The results robustly confirm a common pattern of preferences among recreationists for more complex forest structures. Respondents clearly prefer: taller trees $(24 m>18 m>8 m)$, mixed forests of two species (preferred over single-species forests or monocultures), multiple tree layers (multiple layers $>$ two layers $>$ single layer), a greater number of tree species in mixed stands $(4>3>2)$, and medium and high levels of deadwood over low level of deadwood (medium> high>low). These results are also exemplified through greater overall WTT for a mature forest, with multiple tree species, multi-layered forests and with deadwood (Figure 2b) compared to a mature, monoculture, single-layered broadleaf forest (Figure 2a). The one-way distance that respondents are willing to travel farther to visit the more diverse, mixed forest (Figure $2 \mathrm{~b}$ ) varies from $2.8 \mathrm{~km}$ in Belarus to $30.9 \mathrm{~km}$ in Scotland.

\section{Significance and policy relevance}

Our study documents that forest provide substantial recreational benefits. This is shown in absolute terms by reporting consumer surplus per person per year and in relative terms by comparing aggregated recreational benefits to value added of forestry and logging activities. Except for Belarus, recreation creates greater economic value than added value from forestry and logging activity. A detailed analysis of all the factors affecting recreational benefits is beyond the scope of this study. However, our study provides evidence that there is a strong positive relationship between forest area and recreational benefits expressed in terms of consumer surplus per person per year. This is an important finding as it shows that the in the last two decades in the forest cover across EU will have substantial positive impact on recreational benefits provided by forests. The scale of recreational benefits will not only depend on forest availability, but also on the quality of forests. As demonstrated in this study, benefits of forest recreation depend on forest characteristics.

These findings have important implications for forest policies and management decisions at a time when Europe's forests are in transition facing an uncertain future. The direct and indirect effects of climate change will expose existing forests to increasing degrees of ecological stress. At the same time, changes to forest management and the expansion of forest areas are the essential corollary of policy ambitions to meet the targets for biodiversity conservation and climate change mitigation as part of nature-based solutions to global challenges ${ }^{13}$. To support these goals, the EU Biodiversity Strategy for $2030^{11}$ has proposed a roadmap for planting at least three billion additional trees in the EU by 2030 according to ecological principles. Even though the effectiveness of such plans to achieve biodiversity conservation has been questioned ${ }^{14,15}$, and that the role of trees for global climate change mitigation is subject to debate ${ }^{16}$, it is evident that environmental drivers and policy interventions that attempt to address these challenges will change forests and landscapes in the decades to come. This calls for robust assessments of the relative importance of ecosystem services provided by forests to maximise the social benefits and economic welfare gains from forest management and policy decisions.

This study delivers an assessment in relation to the benefits of forest recreation in ten European countries. It clearly documents that forest recreation values are significant and are associated with forest characteristics. This strongly contrasts with the current approach to forest and land-use policy, whereby forest recreation only plays a minor role. Guidance documents informing policy in relation to the forest transition at national and EU level, such as the new EU Forest Strategy ${ }^{10}$, should be urgently adapted to reflect findings of robust economic assessments of recreational values as provided in this study.

\section{Addressing trade-offs within forest management}

Our study compares the economic benefits of forest recreation to the value of forestry and logging, which due to an existing market for timber can be considered the most tangible among the forest ecosystem services. We demonstrate that recreational benefits in all the study countries are between $€ 263$ (for Denmark) and $€ 648$ (Austria) in absolute terms (CS per person per year) and, apart Belarus, are between 1.15 (Czech Republic) and 7.32 (Switzerland) times greater than the added value from forestry and logging activities (Table 1). This result is obtained despite making conservative assumptions in our travel cost calculation: all respondents who walked or biked to forests were assumed to have zero travel costs. Comparing the benefits of recreation and the added value from forestry and logging provides evidence that can be used to re-calibrate forest policy and related priorities in forest management, to be tailored to the ecological, economic and social context in each country.

Our study shows that forest users across Europe have a clear preference for more complex forest structures. Despite differences across countries, the predominant pattern is that a more diverse forest structure with taller trees, a larger number of mixed tree species and tree layers, and larger amounts of deadwood yield, on average, higher recreational values. This is very important given that mature and mixed forest stands with complex age structures and particularly the presence of deadwood significantly contributes to forest biodiversity ${ }^{17}$. This implies that managing forests to promote recreational values may generate potential synergies with biodiversity conservation ${ }^{18-21}$. 
Optimizing forest ecosystem service provision with trade-offs between timber production and recreation, together with synergies between biodiversity and recreation, requires spatial scale to be considered, from forest stands and landscapes all the way up to regional scale. Joint production at site level may be beneficial if synergies are achievable. However, if management involves significant trade-offs, then spatial differentiation of the management may be preferable. The debates on trade-offs between climate mitigation, biodiversity and effects of forest management on recreation feed into the discussion on how forests in their existing form impact ecosystem service benefits for society. Our study indicates that the majority of forest visits take place during the week. This implies that forest sites located closer to centres of higher population density have higher recreational values. More than 75 per cent of the European population lives in urban settings. Therefore, adopting urban and peri-urban forestry systems that produce more diverse and complex forests can increase overall recreational benefits significantly.

We suggest that the results of this study can form a basis for integrating forest recreational values into ecosystem service models for European forests. The enhanced understanding of the recreational value of forests and its dependency on forest structural attributes can facilitate informed decisions at all scales, within single forest areas, or across forest landscapes and at regional or national level. Acknowledging the potential of forest recreational values to shape the development of European forests is therefore of great importance and must be reflected in policies to implement future forest management strategies.

\section{Methods}

The results presented in this article are based on the findings of an online survey that we designed and distributed to explore visitors' recreation behaviour in forests and preferences for forest characteristics in ten European countries with temperate forests. We study recreation behaviour in forests and estimate the economic value of forest recreation using a travel cost model (TCM). Additionally, using a discrete choice experiment (DCE), we estimate how the value of recreational forest visits depends on forest structural characteristics - and by extension on forest management. Below, we describe the process of data collection, the survey instrument, and the data preparation and analysis.

Survey instrument. The questionnaire consisted of four parts. In the first part, respondents were asked to provide information about the last visited forest. The last visited forest was identified by the respondents using a zoomable map, embedded in the survey and based on Open Street Maps (OSM). The same approach was used to identify information on respondents' place of residence (or the point where the forest trip started). Together, this information enabled the calculation of the travel distance to the last visited forest. Among other things, the first part of the questionnaire also asked for information about the activities carried out during the forest visit, transportation mode, group size during the trip, and, crucially for consumer surplus (CS) estimation, the number of forests visits to the last visited forest and to any other forest in the last 12 months. Information collected in the first part of the survey was used to fit a TCM analysis to estimate CS.

In the second part of the survey, respondents were asked to provide information on the main structural characteristics of their last visited forest, by selecting from a menu of options available. They were also requested to indicate the availability of visitor infrastructure (picnic facilities, trail type) at the last visited site.

The third part of the questionnaire contained a DCE exercise. Respondents were confronted with a series of choice task. In each choice task, respondents were offered two hypothetical forests to visit on their next forest trip as alternatives to the last visited forest (as self-defined by the respondent in the second part of the survey). Study participants were asked to imagine that the context of the next forest trip would be identical to the last forest visit. The distance levels used in the DCE were pivoted around the distance travelled to the last visited forest as reported by the respondent in the first part of the questionnaire. In each choice task, respondents were asked to choose the forest they would prefer to visit, provided that only the three forests presented were available. In the final part of the questionnaire respondents were asked about their socio-demographic profile.

Data collection. The survey was distributed online to a sample of adult members of the general public in ten European countries: Austria, Belarus, Czech Republic, Denmark, France, Germany, Poland, Scotland, Slovakia and Switzerland. Online panels from renowned market research companies were employed to recruit respondents within each country. Participation was voluntary and respondents were informed that they could withdraw at any time. In all countries, quota-based sampling was implemented to ensure a) that participants made at least one forest visit within the 12 months prior to the survey and b) representativeness of each country's population, based on gender, age, settlement size, education level and regions of residence (Supplementary Information). A copy of the questionnaire is available in Supplementary Materials.

Data were collected in January and February 2017, following extensive pre-testing and piloting. The online implementation of all national questionnaires was hosted on a server owned by Kantar Millward Brown in Warsaw. This ensured consistency of data collection across all countries. The survey lives up to the ethical standards of the participating universities. The details on sample sizes by country are reported in Supplementary Information.

Data and approaches to benefit estimation using TCM. In order to calculate the aggregate annual recreational benefits, we estimated (i) the average benefits per forest visit, in terms of consumer surplus (CS), and used information on (ii) the total number of forest visits taken by a country's population over a one-year period. To estimate the average per trip value we assume that data on the last visited forests (travelled distance and number of trips) across the sample are representative for the annual forest visits and apply individual travel cost method. We use the truncated negative binomial model ${ }^{22}$ which accommodates overdispersion and truncation at zero. CS value per person per trip is calculated by $-1 / \beta_{\mathrm{c}}$, where $\beta_{\mathrm{c}}$ is the TC coefficient. The standard errors are obtained using the Delta Method ${ }^{23}$. Country specific TCM results are reported in Table S 8.

To avoid confounding recreational benefits with other unrelated activities carried out during the trip all multiple-purpose and trips longer than one day were not included in the analysis. We calculate individual travel cost per trip as the sum of travel related expenditure ("travel cost": TC; this includes expenditure for gasoline or tickets for public transportation) and the opportunity cost of time ("value of travel time": VTT). Both TC and VTT require information on travel distance.

Page 5/10 
The calculation of travel distance was based on relevant points (forest location and point of departure) as reported by the respondents on the OSM-based maps in the survey. Given the coordinates of the locations of the forest and the departure point on the map, we calculated travel distance as the Euclidean distance between the two points, applying a wiggle factor of 1.2 to the derived estimates ${ }^{24}$.The estimated travel distance is used to calculate the trip expenditure to the forest by car. We assume a mileage of 7 litres $/ 100 \mathrm{~km}$, two persons per car, average mileage costs and considered country-specific gasoline prices at the time of the survey (https://autotraveler.ru/en/spravka/fuel-price-in-europe.html).

The estimated travel distance is also used to derive trip duration for the VTT calculations applied to visitors who reached the forest by car or public transport. For this purpose, we assume an average travel speed of $60 \mathrm{~km} / \mathrm{h}$. Given a relatively large share of respondents who refused to state their personal income in the survey (Table S 2), we assume the VTT to be equal to $1 / 3$ of hourly country specific wage rates, that represents a standard approach in the TCM literature ${ }^{25}$.Wage rates are derived from OECD statistics for all countries studied (https://stats.oecd.org/Index.aspx?DataSetCode=ANHRS). This ensures that CS estimates across countries are comparable, because the VTT is accounted for in exactly the same way across all case study areas in our study. For visitors who went to the forest by bike or on foot (on average: $7.3 \%$ of our sample reported to cycle and $31.1 \%$ to walk to the forest), we conservatively assume that both TC and VTT are zero.

As the first step total travel cost (sum of TC and VTT) enters the TCM together with data on number of forest visits to derive average per trip CS estimates. In the second step, total number of forest trips per country, is derived by calculating the product of the average number of annual forest visits per person and the population aged 18+ of a country) adjusted by the proportion of the sample who stated to have visited a forest in the last year (Table S3, Supplementary Materials). National level recreational estimates are calculated by multiplying average per trip CS by the total number of forests trips.

Because travelled distance (Table 2) differs substantially between weekday and weekend trips, recreational trips are grouped into two categories depending on when the last forest visit took place: (i) weekday trips and (ii) trips taken during weekends/holidays. In Table 1, CS estimates are therefore reported by country and trip category (called 'weekday' if during the week or 'weekend' if at weekends or during holidays).

Aggregate consumer surplus estimates reported in Table 1 represent the net recreational value of forests. We then compared these with the aggregate values of logging to provide an estimate of the relative importance of forest recreation relative to more established economic activities in forests. Directly comparable values of the net benefits of timber production (consumer surplus and producer surplus) are not available. A proxy for the economic value of logging activities can, however, be obtained by multiplying unit price of timber times quantity of timber logged 26,27 . In our study, the value of timber production was based on the Eurostat data on annual gross value added of forestry and logging activities.

Data and approach to valuing the benefits of forest structural characteristics using DCEs. For the design of the DCE, main forest structural attributes and their relevant levels had to be identified on a management-intensity gradient from less to more natural forests ${ }^{28}$. The landscape and forestry literature provides a long list of potential attributes. In our study, we operationalized the most important forest characteristics, as identified by Giergiczny et al. ${ }^{8}$ and Filyshkina et $\mathrm{al}^{9}$. The relevance of these forest characteristics was confirmed in numerous pretests in all the countries considered in our study and focus groups in Denmark and Poland. The attributes are:

Tree height - the height of the upper tree storey in the forest. Levels: $\mathbf{8 m} ; \mathbf{1 8 m} ; \mathbf{2 4 m}$. To visualize the scale of the trees an icon of an average-sized person was added to each visualization.

Forest layer - variation in the structure of the forest. Levels: Single: forest composed of a single layer (age class); Two: forest with trees of two layers; Multiple: forest with multiple layers.

Number of tree species and forest type - refers to the number of tree species within a stand. Levels: 1 and 2 tree species for broadleaved and coniferous forests and 2, 3, 4 for mixed forest. Graphics of Scots pine (Pinus sy/vestris) and Norway spruce (Picea abies) were employed to visualize coniferous species, oak (Quercus robur) and beech (Fagus sylvatica) to visualize broadleaved tree species.

Deadwood - this attribute refers to the amount of natural deadwood (standing and fallen) in the forest. Levels: Low; Medium; High. Respondents were informed that this attribute refers to large pieces of natural deadwood to avoid confusion with the presence of residuals from harvesting and thinning.

Visitor infrastructure - this attribute refers to the presence of infrastructure for visitors in the forest. Levels: None; Picnic sites; Trails; Picnic sites \& trails. As this attribute is unrelated to the topic of this paper - forest structures - results for it are only reported in Table S 7.

Distance to forest - refers to the distance to the forest from an individual's home (or any other location where the trip to the forest would start). The levels of distance used were pivoted depending on the actual distance reported by a respondent for the last visit using 5 sets of distance levels, with 6 levels in each set (Supplementary Materials, Table S 4).

Substantial effort was devoted to adequately explaining the forest characteristics. A novel approach of our study is that respondents learned about the DCE attributes by defining the structural forest characteristics of the last visited forest during the survey, using visual aids to indicate the attribute levels that were perceived to best match the last visited forest. The resulting forest was visualized and included as a third alternative in the choice tasks (see questions Q37Q41). After completing the matching exercise with all attributes, an illustration of a forest profile combining all attributes was instantly generated and shown on the screen. Respondents were asked (on a scale 0-100) to rate how well the generated illustrations resemble the perception of the forest they had visited. Responses are consistent across the countries and relatively high with an average score ranging from 71 for Slovakia to 77 for Belarus (Table S 6 ).

The efficient experimental design composed of 36 choice sets assigned into 3 blocks has been generated using NGENE software. The design for the main survey was generated using priors obtained from the pilot experiment. The final design was optimized for median Bayesian D-error of the MNL model29,30

Page $6 / 10$ 
based on data from a total of 900 pilot interviews. Across respondents, we randomized the order of choice tasks presented to counter-balance possible ordering and anchoring effects ${ }^{31}$. The same experimental design was applied in all 10 countries. Since in the TCM part only single purpose and one day visitors were included, country specific sample sizes and socio-demographics in the DCE part are different (see Table S 5).

The choices recorded enabled us to estimate the marginal rate of substitution (MRS) between having a forest characteristic present in the forest and travel distance. The trade-offs between forest characteristics and distance indicate the relative value of forest characteristics in terms of Willingness to Travel (WTT). WTT represents the number of additional kilometers that a person would be willing to travel to visit a forest with the characteristic of interest (relative to a baseline level), all else equal. We derive WTT estimates directly from the coefficients of a mixed logit model estimated in WTP space ${ }^{32}$ with correlated random parameters (full covariance matrix). Country specific DCE results are reported in Table S 7. Figure 3 shows the strength of preferences in terms of WTT within and across forest characteristics. To generalise information on preferences across all countries (Figure 4), pairwise comparisons are conducted between combinations of model coefficients for each forest characteristic shown in Figure 3. Each forest characteristic has three levels, implying estimation of three comparisons for each characteristic. In the pairwise comparisons, we assign a point to each level of a forest characteristic if its WTT is significantly greater ( $5 \%$ significance level), indicating stronger preference, compared to the competing level. For each country, each level of a forest characteristic can score a maximum of 2 points, and across the 10 countries, the maximum score is 20 . Within a specific forest characteristic, scores closer to 20 indicate common dominance of a level across countries (Figure 4).

\section{Data and code availability}

DCE data and used code are available at: http://czaj.org/pub/materials/gea_2021.zip.

\section{References}

1. McDowell, N. G. et al. Pervasive shifts in forest dynamics in a changing world. Science 368, eaaz9463 (2020).

2. Holl, K. D. \& Brancalion, P. H. S. Tree planting is not a simple solution. Science 368, 580-581 (2020).

3. Fares, S., Mugnozza, G. S., Corona, P. \& Palahí, M. Sustainability: Five steps for managing Europe's forests. Nature 519, 407-409 (2015).

4. Austin, K. G. et al. The economic costs of planting, preserving, and managing the world's forests to mitigate climate change. Nature Communications 11 , 5946 (2020).

5. Elomina, J. \& Pülzl, H. How are forests framed? An analysis of EU forest policy. Forest Policy and Economics 127, 102448 (2021).

6. Clawson, M. \& Knetsch, J. L. Economics of Outdoor Recreation. (Resources for the Future, 1966).

7. Zandersen, M. \& Tol, R. S. J. A meta-analysis of forest recreation values in Europe. Journal of Forest Economics 15, 109-130 (2009).

8. Giergiczny, M., Czajkowski, M., Zylicz, T. \& Angelstam, P. Choice experiment assessment of public preferences for forest structural attributes. Ecological Economics 119, 8-23 (2015).

9. Filyushkina, A., Agimass, F., Lundhede, T., Strange, N. \& Jacobsen, J. B. Preferences for variation in forest characteristics: Does diversity between stands matter? Ecological Economics 140, 22-29 (2017).

10. The European Commission. EU Forest Strategy. https://ec.europa.eu/info/law/better-regulation/have-your-say/initiatives/12674-Forests-new-EUstrategy_en (2021).

11. The European Commission. Biodiversity Strategy for 2030. https://ec.europa.eu/environment/strategy/biodiversity-strategy-2030_en (2020).

12. Mariel, P. et al. Environmental Valuation with Discrete Choice Experiments Guidance on Design, Implementation and Data Analysis. (2021).

13. Seddon, N. et al. Understanding the value and limits of nature-based solutions to climate change and other global challenges. Philosophical Transactions of the Royal Society B: Biological Sciences 375, (2020).

14. Gómez-González, S., Ochoa-Hueso, R. \& Pausas, J. G. Afforestation falls short as a biodiversity strategy. Science 368, 1439 LP - 1439 (2020).

15. Selva, N., Chylarecki, P., Jonsson, B.-G. \& Ibisch, P. L. Misguided forest action in EU Biodiversity Strategy. Science 368,1438 LP - 1439 (2020).

16. Luyssaert, S. et al. Trade-offs in using European forests to meet climate objectives. Nature 562, 259-262 (2018).

17. Europe, F. State of Europe's Forests 2020. (2020).

18. Olschewski, R. et al. Policy Forum challenges and opportunities in developing new forest governance systems: Insights from the IPBES assessment for Europe and Central Asia. Forest Policy and Economics vol. 97 175-179 (2018).

19. Seidl, R. et al. Forest disturbances under climate change. Nature climate change 7, 395-402 (2017).

20. Messier, C. et al. The functional complex network approach to foster forest resilience to global changes. Forest Ecosystems 6, 21 (2019).

21. Jactel, H. et al. Tree Diversity Drives Forest Stand Resistance to Natural Disturbances. Current Forestry Reports 3, 223-243 (2017).

22. Englin, J. \& Shonkwiler, J. S. Estimating social welfare using count data models: an application to long-run recreation demand under conditions of endogenous stratification and truncation. Review of Economics \& Statistics 77, 104-112 (1995).

23. Greene, W. H. Econometric Analysis. (Pearson, 2018).

24. Cooper, J. C. The Use of Straight Line Distances in Solutions to the Vehicle Scheduling Problem. Journal of the Operational Research Society 34, 419-424 (1983).

25. English, E., Leggett, C. \& McConnell., K. Value of Travel Time and Income Imputation. (2015).

26. Heal, G. Valuing Ecosystem Services. Ecosystems 3, 24-30 (2000).

27. Costanza, R. et al. The value of the world's ecosystem services and natural capital. Nature 387, 253-260 (1997).

Page $7 / 10$ 
28. Peterken, G. Natural Woodland: Ecology and Conservation in Northern Temperate Regions. (Cambridge University Press, 1996).

29. Scarpa, R. \& Rose, J. M. Design efficiency for non-market valuation with choice modelling: how to measure it, what to report and why*. Australian Journal of Agricultural and Resource Economics 52, 253-282 (2008).

30. Bliemer, M. C. J., Rose, J. M. \& Hess, S. Approximation of bayesian efficiency in experimental choice designs. Journal of Choice Modelling 1, 98-126 (2008).

31. Day, B. \& Pinto Prades, J.-L. Ordering anomalies in choice experiments. Journal of Environmental Economics and Management 59, 271-285 (2010).

32. Train, K. \& Weeks, M. Discrete Choice Models in Preference Space and Willingness-to-Pay Space. in Applications of Simulation Methods in Environmental and Resource Economics. The economics of Non-Market Goods and Resources (eds. Scarpa, R. \& Alberini, A.) (2005).

\section{Figures}

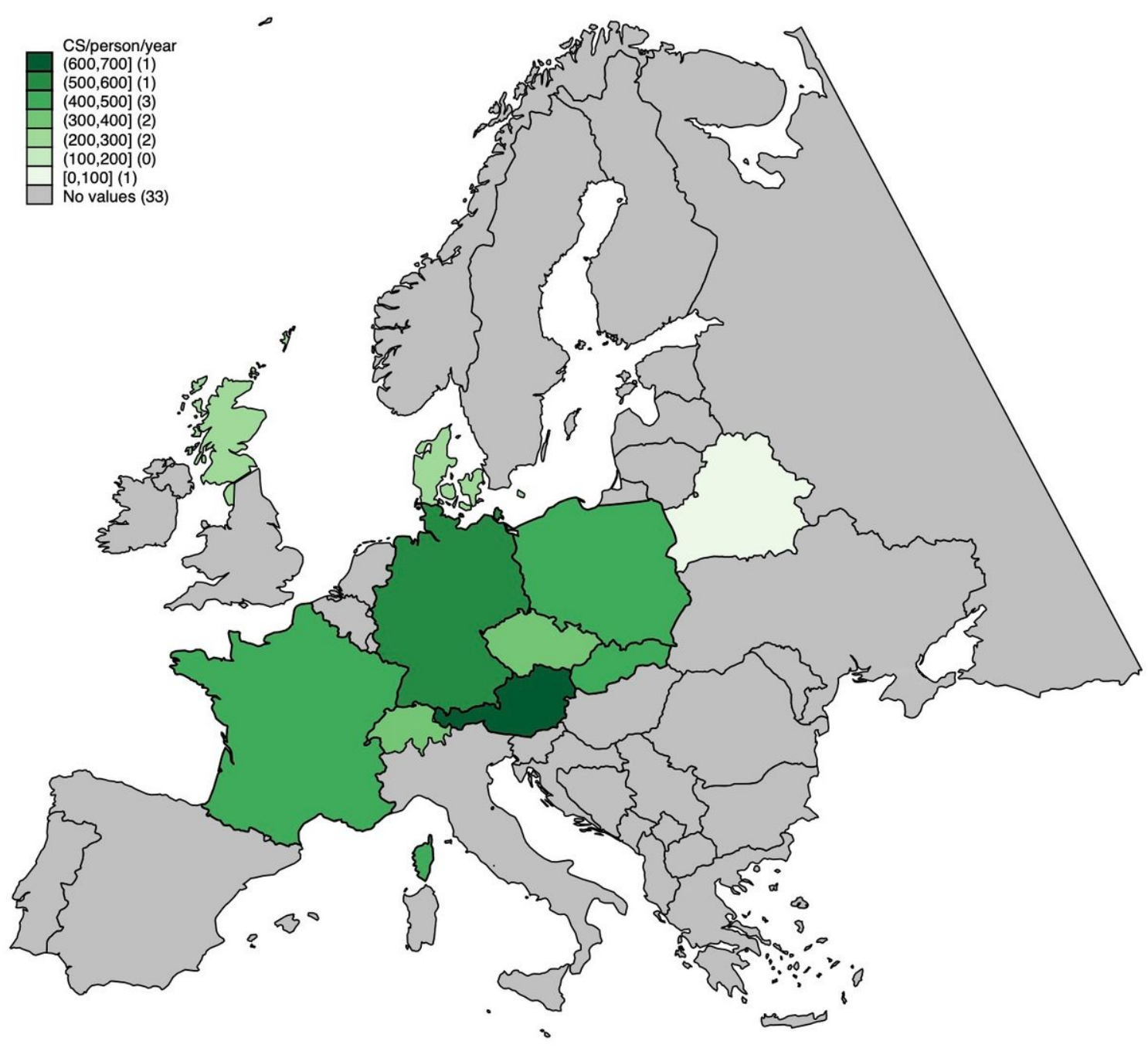

Figure 1

Annual total per capita consumer surplus (CS, in EUR 2017 PPP adjusted) of forest recreation in the ten study countries. 

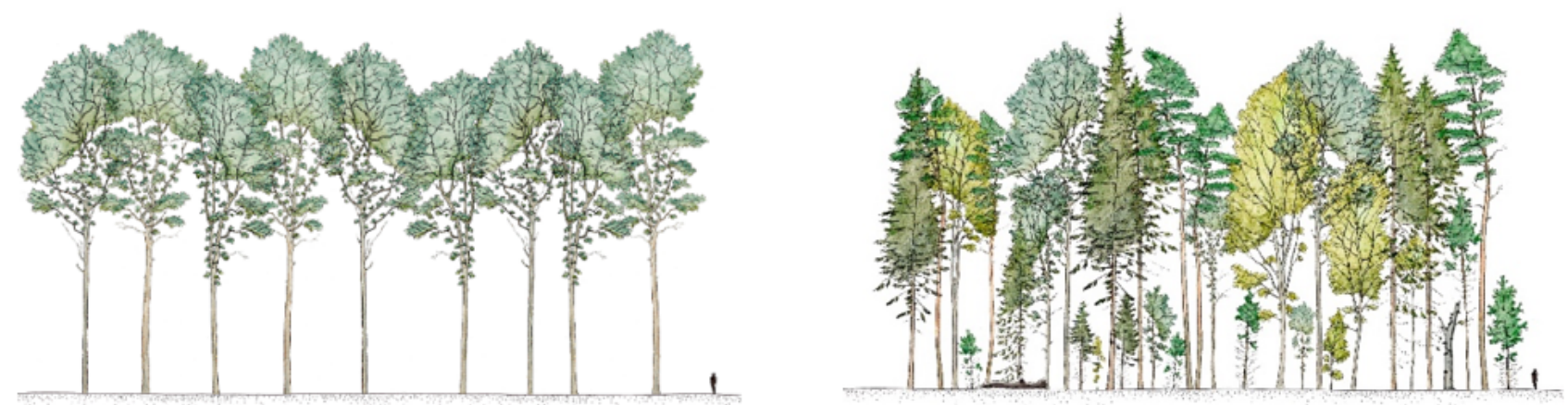

Figure 2

Example of illustrations used to elicit preferences for forest structural characteristics. Panel a) illustrates one of the least preferred type of forests by the survey respondents: a mature, monoculture, single-aged broadleaf forest (see Figure S 1 in Supplementary Materials for an example of a choice task); Panel b) illustrates one of the most preferred type of forest by survey respondents: a mature forest, with multiple tree species, multi-aged plants and with deadwood. Comparing the willingness to travel between the two forests reveal that respondents are on average willing to travel $x \mathrm{~km}$ farther (one way) to visit the forest presented in panel b); AUT: $x=17.9$, BLR: $x=2.8$, CHE: $x=12.1$, CZE: $x=22.1$, DEU: $x=13.2$, DNK: $x=13.3, F R A: x=25.6, P O L: x=22.5$, SVK: $x=42.5$, SCO: $x=30.9$.

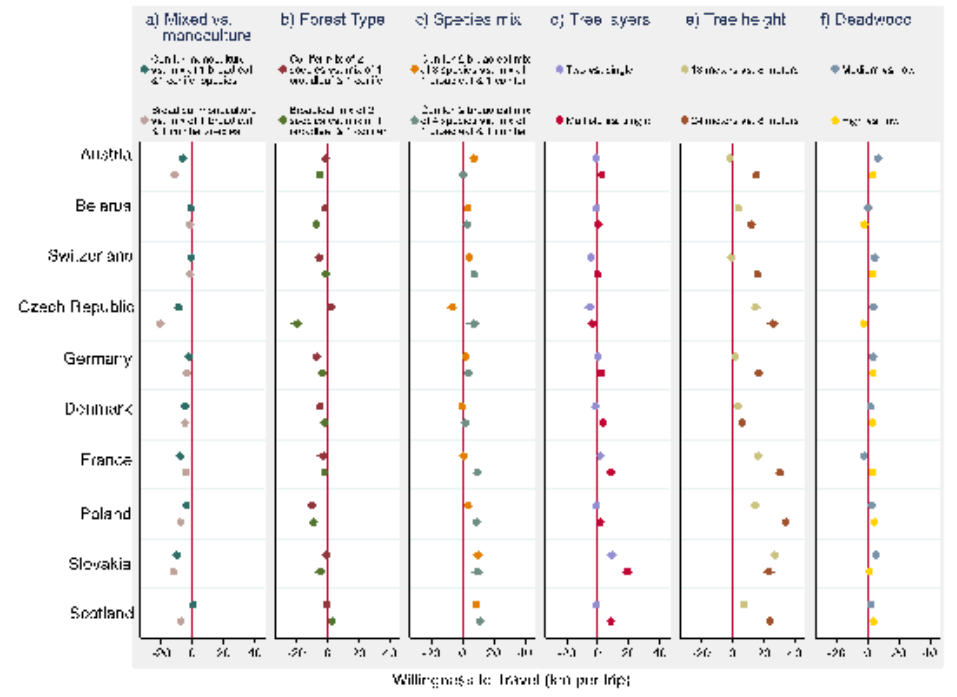

Figure 3

Willingness to travel farther/nearer than a forest with the baseline levels by country. 


\section{Tree layers}

Forest type

\section{Mixed vs. Monoculture}

Species mix

Deadwood

\section{Tree height}

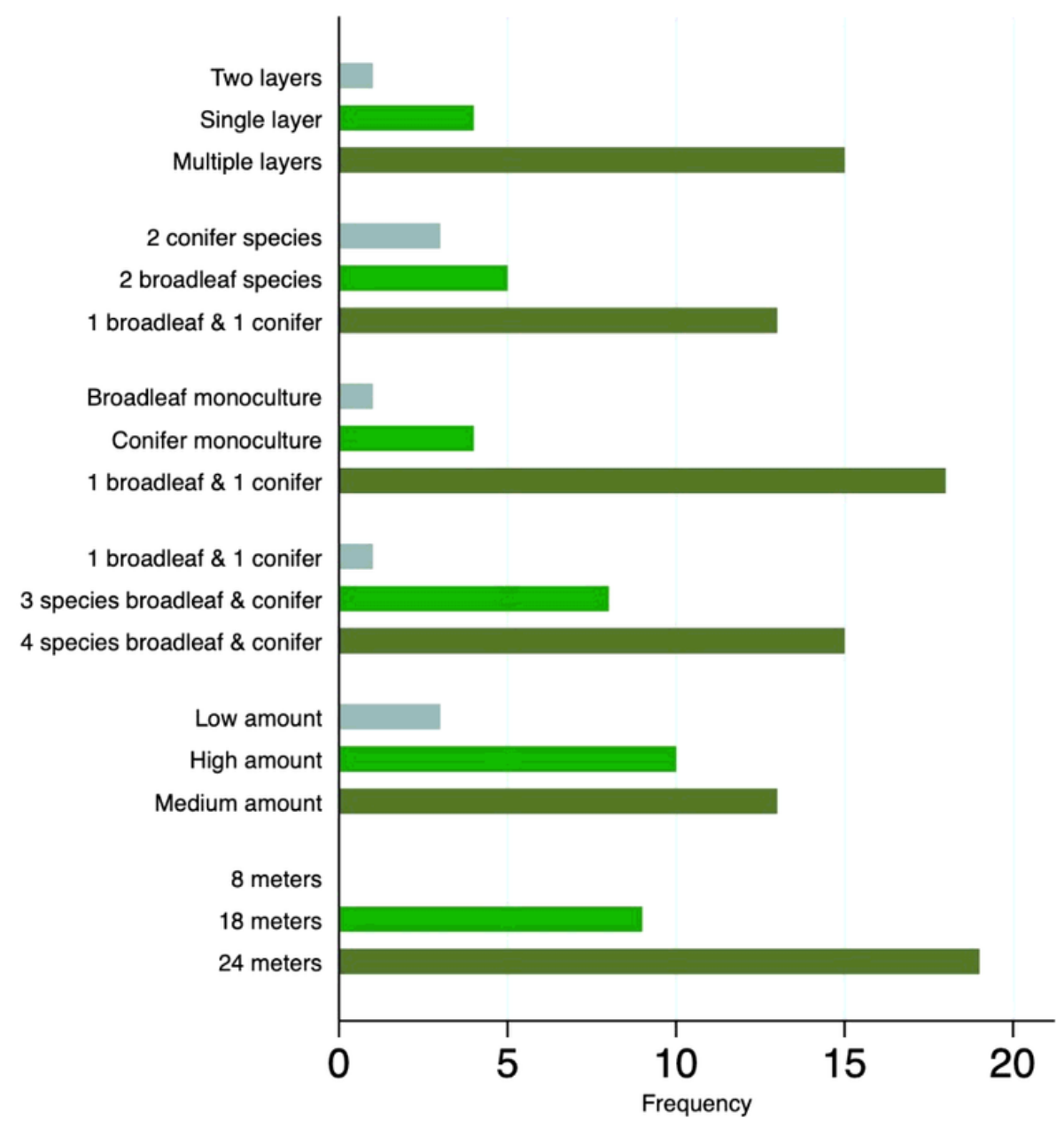

Figure 4

The number of times that the WTT for a particular level of a forest structural attribute is significantly (95\%) greater than the WTT for the remaining levels of that attribute (aggregated across all 10 countries). The maximum possible number of comparisons and therefore the highest score for each attribute level is 20 ( 2 relevant comparisons with remaining levels $\times 10$ countries). A value of 20 indicates that an attribute level dominates other levels in all countries.

\section{Supplementary Files}

This is a list of supplementary files associated with this preprint. Click to download.

- SM.docx 